\title{
Olfactory bulb ablation: Effects on handling reactivity, open-field behavior, and agonistic behavior in male and female hamsters
}

\author{
WILLIAM N. HILGER, JR. and FRANK A. ROWE \\ Illinois Institute of Technology, Chicago, Illinois 60616
}

\begin{abstract}
Bilateral olfactory bulb ablation resulted in increased handling reactivity, and decreased open-field ambulation and intraspecific aggressiveness in male and female hamsters. Bulbectomy-induced increases in handling reactivity were greater in female than in male hamsters. However, bulbectomy-induced deficits in open-field ambulation and aggressive behavior were greater in males than in females. Bulbectomy-induced increases in handling reactivity were transient in both males and females. Furthermore, bulbectomized females regained preoperative levels of open-field ambulation by the second postoperative week. In contrast, bulbectomized males exhibited levels of open-field ambulation that were below preoperative levels in all but the third postoperative week. In bulbectomized males, aggressiveness was suppressed for the duration of postoperative testing.
\end{abstract}

Olfactory bulb ablation has been found to alter both social and nonsocial behaviors in several rodent species. Social behaviors that are altered by bulbectomy include sexual behavior in male mice (Rowe \& Edwards, 1972), rats (Bermant \& Taylor, 1969; Heimer \& Larsson, 1967), and hamsters (Murphy \& Schneider, 1970); sexual behavior in female mice (Thompson \& Edwards, 1972) and rats (Edwards \& Warner, 1972; Moss, 1971); and aggressive behavior in male mice (Ropartz, 1968; Rowe \& Edwards, 1971) and hamsters (Murphy \& Schneider, 1970). Among the nonsocial behaviors that have been found to be affected by bulbectomy are active and passive avoidance learning in rats (Sieck, 1972; Sieck \& Gordon, 1972, 1973), open-field activity in rats (Sieck, 1972), running-disk activity in hamsters (Borer, Powers, Winans, \& Valenstein, 1974), and handling reactivity in rats (Douglas, Isaacson, \& Moss, 1969) and hamsters (Goodman \& Firestone, 1973).

In some instances, the nature of the behavioral change produced by bulbectomy appears to be a function of the sex of the bulbectomized animal. Thus, while bulbectomy produces a deficit in the sexual behavior of male rats (Bermant \& Taylor, 1969; Heimer \& Larsson, 1967), in female rats bulbectomy has been reported to facilitate the hormonal induction of sexual receptivity (Edwards \& Warner, 1972; Moss, 1971). A similar situation appears to exist in hamsters in which bulbectomy has been reported to abolish sexual behavior in males (Murphy \& Schneider, 1970), while having little or no influence on sexual receptivity in females (Carter, 1973; Leonard, 1972).

There have been few experimental efforts aimed at

This experiment was part of a thesis submitted to Illinois Institute of Technology by William N. Hilger in partial fulfillment of the requirements for the MS in psychology. Reprint requests should be addressed to Frank A. Rowe. determining whether or not there are sex differences in the influence of bulbectomy on nonsocial behaviors and on social behaviors other than mating behavior. The present experiment was designed to investigate the influence of olfactory bulbectomy on handling reactivity and open-field ambulation in male and female hamsters. Furthermore, since hamsters of both sexes exhibit a propensity to fight, we examined the influence of bulbectomy on intraspecific aggressive behavior in male and female hamsters. Although there is evidence indicating that bulbectomy reduces aggressiveness in male hamsters (Murphy \& Schneider, 1970), reports of the effects of bulbectomy on aggressive behavior in female hamsters are contradictory. Leonard (1972) reported that bulbectomy attenuated the increase in aggressiveness normally seen in female hamsters following copulation and during lactation. However, Carter (1973) failed to observe any effect of bulbectomy on postcopulatory increases in aggressiveness in female hamsters.

\section{METHOD}

\section{Materials and Procedure}

Subjects for this experiment were male and female golden hamsters obtained from a commercial supplier (A. R. Schmidt, Madison, Wisconsin). All animals were approximately 60 days old at the start of the experiment. Upon their arrival at the laboratory, all hamsters were housed individually in cages $\left(30.5 \mathrm{~cm}^{3}\right)$ constructed of Novaply with hardware cloth tops. Cage floors were covered with San-I-Cel bedding, and food, water, and paper toweling for nest material were available ad lib. A reversed light-dark cycle ( $12 \mathrm{~h}$ light $-12 \mathrm{~h}$ dark) was in effect in the colony room, and all behavioral tests were conducted during the first half of the dark phase of the cycle.

Each animal received 4 weeks of preoperative testing. In each of these weeks, behavioral tests were conducted according to the following schedule: 1 st and 2 nd days, handling reactivity; 2 nd 
and 3rd days, open-field ambulation; 4th and 5th days, aggression testing. All animals were weighed each week following the first test of handling reactivity.

Handling reactivity. The handling reactivity test was a modified version of the test developed by King (1958) for use with rats. The test consisted of rating each of five response categories on a four-point scale. The response categories were: (1) response to a presented object (pencil), (2) resistance to capture, (3) resistance to handling, (4) urination and defecation, and (5) cataplexy. For each category, a score of one indicated minimal responsiveness, while a score of four indicated maximal responsiveness. On a given day, each animal's scores on all response categories were summed to yield a single handlingreactivity score for that day. Each week, an animal's handling reactivity was expressed as the average of the total scores from the two tests for that week.

Open-field test. Open-field testing was conducted on a $91.5 \mathrm{~cm}^{2}$ plywood platform having walls $30.5 \mathrm{~cm}$ high. The platform was painted white and was divided by black lines into squares $22.9 \mathrm{~cm}$ on a side. Each open-field test lasted for $5 \mathrm{~min}$ and consisted of placing an animal in one corner of the platform and recording the number of squares it completely traversed in the allotted time. Before each animal was tested, the platform was wiped down with a cloth dampened with a dilute vinegar solution to minimize the influence of odors left by the preceding animal. Each week, an animal's open-field ambulation was expressed as the average number of squares traversed in the two tests for that week.

Aggression test. Tests of aggressive behavior were conducted in 5-gal glass aquariums ( $30.5 \times 20.3 \times 30.5 \mathrm{~cm}$ high $)$, the floors of which were covered with San-I-Cel. Each test of aggression was 10 min long and consisted of pairing an experimental animal with a gonadally-intact, group-caged stimulus animal of similar weight $( \pm 5 \mathrm{~g})$. During each test, the frequency with which the experimental animal initiated the following behaviors was recorded: (1) investigation, in which the experimental animal brought its nose into contact with any part of the body of the stimulus animal; (2) wrestling, in which the experimental and stimulus animals were in physical contact and were rolling about on the floor of the test cage without biting; (3) attack-chase sequences, in which the experimental animal made a biting attack on the stimulus animal, which fled and was pursued by the experimental animal; (4) fighting, similar to wrestling, except that there was conspicuous biting of the stimulus animal by the experimental animal; (5) marking, in which the experimental animal rubbed its flank glands on the walls of the test cage; and (6) self grooming.

If aggression was assessed only in homosexual encounters, it is conceivable that differences in aggressiveness between male and female hamsters might reflect sex differences in the aggression-eliciting properties of the stimulus animals. Therefore, in the present experiment, one half of the experimental animals encountered a stimulus animal of the same sex in the first week of aggression testing, a stimulus animal of the opposite sex in the second week, and so on. The remaining half of the experimental animals encountered stimulus animals of the same and opposite sex in the reverse order. If an experimental female happened to be in heat on a day that she was scheduled for a test of aggression, the test was postponed for $24 \mathrm{~h}$. Similarly, stimulus females were not used in aggression tests when they were in heat.

At the conclusion of the fourth week of preoperative testing, hamsters of each sex were allocated randomly to one of the following surgical treatments: bilateral olfactory bulb removal, unilateral olfactory bulb removal, or sham surgery. All surgery was performed while animals were anesthetized with $90 \mathrm{mg} / \mathrm{kg}$ bwt of sodium pentobarbital preceded by an injection of atropine sulphate. Olfactory bulb removal was accomplished by aspiration, and details of the surgical procedure have been described elsewhere (Rowe \& Edwards, 1972). There were six males and six females in each surgical condition.

Behavioral testing was initiated $48 \mathrm{~h}$ after surgery and was continued for 4 weeks. The scheduling of weekly tests of handling reactivity, open-field behavior, and aggressive behavior was identical to that described for preoperative tests, as was the order of presentation of same and opposite sex stimulus animals in the tests of aggressive behavior. Animals were coded in such a manner that the person conducting the behavioral tests was unaware of the surgical condition to which each animal belonged.

Following the last postoperative test of aggressive behavior, all bilaterally and unilaterally bulbectomized animals were perfused intracardially with physiological saline followed by $10 \%$ formalin. Brains were removed from the skulls, and the extent of olfactory bulb damage was assessed by examining 20 micra horizontal sections stained with cresyl violet.

\section{RESULTS}

\section{Handling Reactivity}

Initially, female hamsters scored higher than males in preoperative tests of handling reactivity. However, hamsters of both sexes showed decreases in handling reactivity from the first to the fourth preoperative week. By the fourth preoperative week, there were no differences in handling reactivity among males and females that were allocated to the different surgical conditions. Bilateral olfactory bulb ablation resulted in increased handling reactivity scores in both male and female hamsters $(F=5.05, \mathrm{df}=2 / 30, \mathrm{p}<.05)$, the magnitude of the increase being greater in bilaterally bulbectomized females than in similarly treated males. In contrast to bilateral bulbectomy, unilateral bulbectomy and sham surgery had no influence on handling reactivity in male or female hamsters.

Table 1

Mean ( \pm 1 SE) Postoperative Handling Reactivity Scores

\begin{tabular}{llrccc}
\hline & & \multicolumn{4}{c}{ Postoperative Week } \\
\cline { 3 - 5 } & & 1 & 2 & 3 & 4 \\
\hline \multirow{4}{*}{ Males } & Bilateral & $8.16 \pm 0.74$ & $5.91 \pm 0.32$ & $5.00 \pm 0.00$ & $6.66 \pm 0.77$ \\
& Unilateral & $5.33 \pm 0.16$ & $5.33 \pm 0.24$ & $5.25 \pm 0.24$ & $5.00 \pm 0.00$ \\
& Sham & $5.50 \pm 0.25$ & $5.08 \pm 0.08$ & $5.00 \pm 0.00$ & $5.00 \pm 0.00$ \\
& Bilateral & $11.16 \pm 1.61$ & $6.33 \pm 0.92$ & $6.08 \pm 0.55$ & $5.25 \pm 0.24$ \\
Females & Unilateral & $7.16 \pm 0.55$ & $5.25 \pm 0.17$ & $5.16 \pm 0.10$ & $6.41 \pm 1.14$ \\
& Sham & $6.16 \pm 0.30$ & $5.50 \pm 0.57$ & $5.66 \pm 0.33$ & $6.16 \pm 0.90$ \\
\hline
\end{tabular}


The effect of bilateral bulbectomy on handling reactivity was transient. By the second pair of postoperative tests (Postoperative Days9 \& 10), and in all subsequent tests, handling reactivity scores of bilateral males and females approximated the scores obtained by unilaterally bulbectomized and sham-operated animals of the same sex. Table 1 summarizes the handling reactivity data for males and females in each surgical condition.

\section{Open-field Behavior}

Preoperatively, there were no differences in open-field ambulation among male and female hamsters assigned to the different surgical conditions. Postoperative tests of open-field ambulation were conducted on the $3 \mathrm{rd}$ and 4 th days after surgery, and at weekly intervals thereafter for the duration of the experiment. Bilateral bulbectomy resulted in a marked reduction in the number of squares traversed by both male and female hamsters in the first postoperative week $(\mathrm{F}=8.31, \mathrm{df}=2 / 30, \mathrm{p}<.01)$, and the reduction in open-field ambulation was greater in bilateral males than in bilateral females $(F=4.82$, $\mathrm{df}=2 / 30, p<.05)$. Not only was the postoperative decrease in the number of squares traversed greater in bilateral males than in bilateral females, but open-field ambulation remained depressed longer in the males than in the females. By the second week of postoperative testing, the number of squares traversed by bilaterally bulbectomized females was comparable to the number of squares they traversed in the last preoperative week. In the third and fourth postoperative weeks, bilateral females exceeded preoperative levels of open-field ambulation. In contrast to female hamsters, bilaterally bulbectomized males exhibited levels of open-field ambulation that were below preoperative levels in all but the third postoperative week (Figure 1).

Unilateral bulbectomy and sham surgery had little or no influence on open-field ambulation in male or female hamsters. Unilaterally bulbectomized females showed a decrease in the number of squares they traversed in the first and second postoperative weeks. However, with the exception of the second postoperative week, unilateral females exhibited levels of open-field ambulation that were statistically comparable to those exhibited by sham-operated females. Unilaterally bulbectomized and sham-operated male hamsters exhibited comparable levels of open-field ambulation in all but the fourth postoperative week. In the latter instance, unilateral and sham-operated males differed in the number of squares they traversed due to an increase in open-field activity by unilateral males and a concomitant decrease in open-field activity by sham-operated males.

\section{Agonistic Behavior}

Investigatory Behavior. Preoperatively, male hamsters engaged in investigation of stimulus animals

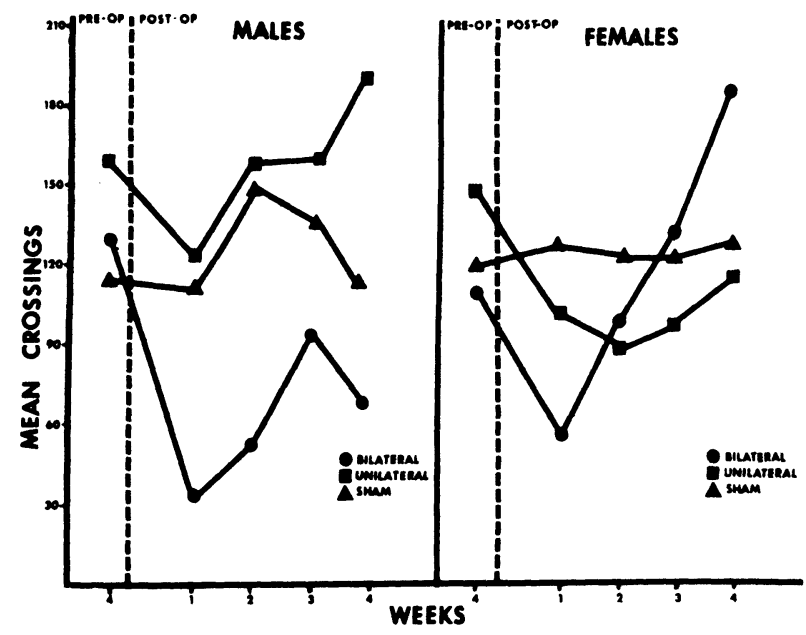

Figure 1. Mean number of squares traversed by male and female hamsters in each surgical condition.

of both sexes more often than did females $(\mathrm{F}=80.33$, df $=1 / 30, \mathrm{p}<.01)$. Furthermore male hamsters investigated stimulus females more often than they investigated stimulus males in preoperative encounters $(F=6.55, \mathrm{df}=1 / 30, \mathrm{p}<.05)$. On the other hand, female hamsters investigated stimulus animals of both sexes equally often prior to surgery (Table 2).

Bilateral olfactory bulbectomy resulted in a significant reduction in the number of investigatory contacts initiated by male hamsters, and the reduction was most evident when males were paired against stimulus females $(\mathrm{F}=4.21, \mathrm{df}=1 / 30, \quad \mathrm{p}<.05)$. Consequently, in postoperative encounters, bilateral males investigated stimulus males and stimulus females equally often. Unilateral bulbectomy and sham surgery had no influence on the number of investigatory contacts initiated by male hamsters in either homosexual or heterosexual encounters, and males in these groups continued to investigate stimulus females more than they investigated stimulus males.

No changes were observed in the number of investigatory contacts initiated by female hamsters in homosexual or heterosexual encounters as a consequence of any of the surgical treatments. In postoperative tests, female hamsters continued to investigate stimulus animals of both sexes equally often.

Wrestling and fighting. In the present experiment, episodes of wrestling often culminated in a brief fight. That is, after a brief period of wrestling without biting, the experimental animal often bit the stimulus animal. Furthermore, in some instances, it was difficult to determine whether or not biting did, in fact, occur as the experimental and stimulus animal wrestled. For these reasons, wrestling and fighting were scored as a single response category.

Preoperatively, approximately equal numbers of male 
Table 2

Preoperative and Postoperative Agonistic Behaviors in Male and Female Hamsters (Mean \pm 1 SE)*

\begin{tabular}{|c|c|c|c|c|c|c|}
\hline \multirow{2}{*}{\multicolumn{3}{|c|}{ Sex of Opponent: }} & \multicolumn{2}{|c|}{ Preoperative } & \multicolumn{2}{|c|}{ Postoperative } \\
\hline & & & Male & Female & Male & Female \\
\hline \multirow[b]{2}{*}{ Investigation } & Males & $\begin{array}{l}\text { BL } \\
\text { UL } \\
\text { S }\end{array}$ & $\begin{array}{l}28.0 \pm 2.9 \\
37.3 \pm 5.1 \\
34.8 \pm 2.9\end{array}$ & $\begin{array}{l}51.7 \pm 7.4 \\
53.2 \pm 5.1 \\
69.3 \pm 9.9\end{array}$ & $\begin{array}{l}19.3 \pm 4.6 \\
47.2 \pm 6.8 \\
34.0 \pm 8.6\end{array}$ & $\begin{array}{l}16.7 \pm 5.3 \\
61.2 \pm 8.6 \\
60.3 \pm 1.8\end{array}$ \\
\hline & Females & $\begin{array}{l}\text { BL } \\
\text { UL } \\
\text { S }\end{array}$ & $\begin{array}{r}8.0 \pm 1.6 \\
11.8 \pm 3.0 \\
11.3 \pm 3.5\end{array}$ & $\begin{array}{r}9.3 \pm 1.3 \\
5.8 \pm 3.0 \\
11.3 \pm 3.3\end{array}$ & $\begin{array}{r}6.7 \pm 1.5 \\
12.7 \pm 1.7 \\
13.3 \pm 3.4\end{array}$ & $\begin{array}{r}12.3 \pm 1.8 \\
6.3 \pm 4.3 \\
20.2 \pm 5.7\end{array}$ \\
\hline \multirow[b]{2}{*}{ Wrestle-Fight } & Males & $\begin{array}{l}\text { BL } \\
\text { UL } \\
\text { S }\end{array}$ & $\begin{array}{l}5.2 \pm 1.5 \\
8.5 \pm 1.7 \\
5.7 \pm 1.7\end{array}$ & $\begin{array}{l}4.0 \pm 1.0 \\
4.5 \pm 2.8 \\
6.8 \pm 2.4\end{array}$ & $\begin{aligned} 2.7 & \pm 2.5 \\
13.3 & \pm 3.3 \\
5.7 & \pm 3.3\end{aligned}$ & $\begin{array}{l}2.0 \pm 2.8 \\
6.0 \pm 3.5 \\
7.0 \pm 1.9\end{array}$ \\
\hline & Females & $\begin{array}{l}\text { BL } \\
\text { UL } \\
S\end{array}$ & $\begin{aligned} 8.5 & \pm 2.6 \\
11.8 & \pm 3.0 \\
9.8 & \pm 2.2\end{aligned}$ & $\begin{array}{l}6.2 \pm 4.9 \\
5.8 \pm 3.0 \\
7.8 \pm 2.4\end{array}$ & $\begin{array}{r}8.3 \pm 2.5 \\
12.7 \pm 1.7 \\
12.5 \pm 3.5\end{array}$ & $\begin{array}{l}6.5 \pm 2.9 \\
6.3 \pm 4.3 \\
9.7 \pm 1.9\end{array}$ \\
\hline \multirow{2}{*}{ Attack-Chase } & Males & $\begin{array}{l}\text { BL } \\
\text { UL } \\
S\end{array}$ & $\begin{array}{l}3.8 \pm 1.1 \\
3.8 \pm 1.5 \\
3.6 \pm 2.1\end{array}$ & $\begin{array}{l}3.5 \pm 1.9 \\
3.5 \pm 1.5 \\
3.8 \pm 1.2\end{array}$ & $\begin{array}{l}0.7 \pm 0.9 \\
6.5 \pm 1.9 \\
5.3 \pm 3.8\end{array}$ & $\begin{array}{l}1.3 \pm 0.8 \\
5.5 \pm 1.9 \\
5.8 \pm 2.4\end{array}$ \\
\hline & Females & $\begin{array}{l}\text { BL } \\
\text { UL } \\
S\end{array}$ & $\begin{array}{l}3.5 \pm 1.5 \\
3.6 \pm 0.8 \\
3.5 \pm 1.8\end{array}$ & $\begin{array}{l}3.5 \pm 1.2 \\
3.6 \pm 1.9 \\
5.5 \pm 2.5\end{array}$ & $\begin{array}{r}2.8 \pm 0.3 \\
10.2 \pm 4.5 \\
11.0 \pm 5.7\end{array}$ & $\begin{array}{l}6.6 \pm 2.4 \\
6.3 \pm 2.7 \\
7.6 \pm 2.2\end{array}$ \\
\hline
\end{tabular}

*Means reported in this table are based upon 2 weeks of preoperative testing and 2 weeks of postoperative testing with a stimulus animal of each sex. Means were computed using only those animals that engaged in a particular behavior at least once with a stimulus animal of a particular sex. $B L, U L$, and $S$ designate bilaterally bulbectomized, unilaterally bulbectomized, and sham-operated groups, respectively.

and female hamsters initiated at least one episode of wrestling or fighting with stimulus animals of each sex. However, female hamsters initiated these behaviors more frequently than did males, regardless of the sex of the stimulus animals $(\mathrm{F}=5.52, \mathrm{df}=1 / 30, \mathrm{p}<.05)$.

None of the surgical treatments influenced either the number of female hamsters that initiated wrestling or fighting, or the frequency with which they initiated these behaviors (Table 2). However, bilateral bulbectomy reduced the number of male hamsters that initiated wrestling or fighting in encounters with stimulus males. Furthermore, bilaterally bulbectomized males that continued to initiate these behaviors in homosexual encounters tended to do so less often than in preoperative tests. Although bilateral bulbectomy did not influence the number of males that initiated wrestling or fighting with stimulus females, bilateral males did tend to initiate these behaviors less often than in preoperative encounters.

While sham operations had no influence on the incidence of wrestling or fighting in male hamsters, unilateral bulbectomy resulted in a significant increase in the frequency with which male hamsters initiated these behaviors $(\mathrm{F}=3.82, \mathrm{df}=2 / 30, \mathrm{p}<.05)$. The increase in wrestling and fighting was most evident when unilaterally bulbectomized males were paired against stimulus males; however, the influence of sex of the stimulus animal was not statistically reliable.

Attack-chase sequences. Preoperatively, attack-chase sequences were seen infrequently in male and female hamsters. Postoperatively, unilaterally bulbectomized and sham-operated animals of both sexes showed slight increases in the frequency with which they initiated attack-chase sequences against stimulus animals of both sexes. On the other hand, bilaterally bulbectomized males initiated fewer attack-chase sequences than they did preoperatively, and the reduction in the frequency of occurrence of this behavior was particularly evident when bilateral males were paired against stimulus males. Bilaterally bulbectomized females also showed a reduction in the number of attack-chase sequences that they initiated against stimulus males. However, bilateral bulbectomy did not appear to influence the number of attack-chase sequences initiated by female hamsters in homosexual encounters (Table 2).

Marking, self-grooming, and body weight. Male hamsters marked more often than did females in both preoperative and postoperative tests of aggressive behavior, and the frequency with which males marked was not influenced by the sex of the animal that they were paired against. Most female hamsters never exhibited marking in this experiment. Bilateral olfactory bulbectomy resulted in a reduction in the frequency with which males marked when in the presence of both male and female stimulus animals. However, the influence of bilateral bulbectomy on marking in male hamsters was not statistically reliable.

Male hamsters groomed themselves more often than females prior to surgery, although this difference was not statistically reliable. Bilateral bulbectomy resulted in a slight reduction in the frequency with which male hamsters groomed. 
At the beginning of the experiment, there were no differences in body weight among males and females assigned to the different surgical conditions. None of the surgical conditions influenced weight gain in either males or females, and all hamsters were heavier at the conclusion of the experiment than at its inception. At the conclusion of the experiment, females tended to weigh more than males; however, this difference was not statistically reliable.

\section{Histology}

All bilaterally bulbectomized hamsters exhibited complete removal of the main and accessory olfactory bulbs. In three cases (one male and two females) there was slight, unilateral damage to the frontal cortex. In most unilaterally bulbectomized males and females, all of one main and accessory olfactory bulb had been removed. There was no evidence of cortical damage in unilaterally bulbectomized hamsters, and damage to the remaining olfactory bulb was infrequently observed.

\section{DISCUSSION}

In the present experiment, bilateral olfactory bulb ablation resulted in increased handling reactivity and decreased open-field ambulation and intraspecific aggressiveness in both male and female hamsters. Bulbectomy-induced increases in handling reactivity were greater in female than in male hamsters. However, bulbectomy-induced deficits in open-field ambulation and agonistic behaviors tended to be greater in males than in females.

Our observation that bilateral bulbectomy produced greater changes in handling reactivity in female hamsters than in males is in accord with observations regarding the influence of bulbectomy on handling reactivity in male and female rats. Richman, Gulkin, and Knoblock (1972) reported that fewer of their male rats showed dramatic increases in handling reactivity following bulbectomy than did female rats in a previous experiment (Douglas et al., 1969). In the present experiment, bulbectomy-induced increases in handling reactivity were transient. This observation is in accord with a previous report that, with daily handling, bilaterally bulbectomized female hamsters exhibited preoperative levels of handling reactivity by the end of the first postoperative week (Goodman \& Firestone, 1973). However, our results suggest that extensive daily handling is not necessary for reducing handling reactivity in hamsters of either sex. All of our bulbectomized hamsters exhibited preoperative levels of handling reactivity by the beginning of the second postoperative week, even though they had received only two tests of handling reactivity in the preceding week.

Although both male and female hamsters showed a dramatic reduction in open-field ambulation following bilateral bulbectomy, both the magnitude and duration of the deficit were greater in males than in females. To the extent that ambulation in an open field reflects an animal's general activity level, our data are in accord with Borer et al.'s (1974) observation that bilateral bulbectomy reduced running-disk activity in male and female hamsters. However, behavior in an open field has been reported to be influenced by an animal's emotional responsiveness, and its propensity to explore a novel environment (Whimbey \& Denenberg, 1967). To the extent that increased handling reactivity is indicative of increased emotional reactivity, our data are consistent with observations that suggest that emotionality and open-field ambulation are negatively correlated (Denenberg, 1964; Whimbey \& Denenberg, 1967). In the present experiment, there were no procedures for directly assessing exploratory tendencies in hamsters before and after surgery. However, it is conceivable that open-field behavior in male hamsters is more subject to the influence of bulbectomy-induced changes in both emotionality and exploratory drive than is open-field behavior in female hamsters.

Bilateral olfactory bulb ablation reduced the frequency with which male hamsters investigated stimulus animals of either sex. This observation, along with reports that anosmia produced by destruction of the olfactory epithelium reduced social investigation in male hamsters (Devor \& Murphy, 1973), suggests that social interactions among hamsters are largely dependent upon olfactory stimuli. However, the fact that bilaterally bulbectomized males initiated fewer investigatory contacts with conspecifics than unilaterally bulbectomized and sham-operated males need not be totally a consequence of the fact that bilateral males were deprived of olfactory stimuli emanating from conspecifics. In addition to anosmia, changes in the investigatory behavior of bilaterally bulbectomized males could be a consequence of changes in emotionality, exploratory drive, and/or general activity level, reflecting the loss of nonsensory influences of the olfactory bulbs on other forebrain structures (Cain, 1974). Similarly, the observation that bilateral bulbectomy resulted in male hamsters investigating stimulus males and females equally often could indicate that a male hamster's ability to distinguish between male and female conspecifics is dependent upon olfactory cues. However, it is conceivable that male hamsters can distinguish the sex of conspecifics on the basis of nonolfactory stimuli and that bilateral bulbectomy abolishes a male hamster's preference for females. Which, if either, of these alternatives is the case remains to be determined.

It should be pointed out that our criterion of an investigatory contact did not differentiate between behaviors such as sniffing and licking. Thus, we do not know if compensatory increases in the occurrence of the latter behavior are important for the persistence of some investigatory behavior in bilaterally bulbectomized male and female hamsters.

Although bilateral bulbectomy reduced the frequency of occurrence of wrestling, fighting, and attack-chase sequences in male hamsters, in most instances these 
behaviors were not completely abolished. In this respect, male hamsters differ from male mice, in which bilateral olfactory bulbectomy has been reported to completely abolish intraspecific aggression in most instances (Denenberg, Gaulin-Kremer, Gandelman, \& Zarrow, 1973; Ropartz, 1968; Rowe \& Edwards, 1971). Although bilaterally bulbectomized male hamsters continued to display some aggressive behaviors, there did appear to be a difference between the behavioral context out of which aggressive acts arose before and after surgery. Preoperatively, agonistic behaviors almost always arose out of investigatory contacts initiated by the experimental males. However, following bilateral bulbectomy, males typically initiated aggressive acts only in response to the approach of the stimulus animals. The fact that our bilateral males initiated aggressive acts only in response to contacts initiated by the stimulus animals is in accord with a previous report that bulbectomized male hamsters performed aggressive acts only when attacked by other hamsters (Murphy \& Schneider, 1970).

Bilateral olfactory bulb ablation had a minimal influence on aggressive behavior in female hamsters. This observation, and observations regarding the influence of bilateral bulbectomy on the display of sexual receptivity in female hamsters (Carter, 1973; Leonard, 1972) suggest that the olfactory bulbs are of relatively little importance for the display of social behaviors in female hamsters.

The. present data raise two issues regarding the behavioral changes observed following bulbectomy. The first issue is concerned with whether or not behavioral changes observed following bulbectomy are a consequence of having rendered animals anosmic, or are a consequence of neurophysiological changes resulting from the disruption of olfactory bulb connections with other regions of the brain. The authors know of no data regarding the influence of peripherally-induced anosmia on open-field ambulation in rodents. However, anosmia produced by destruction of the olfactory mucosa has been reported to have no influence on handling reactivity in rats (Cain \& Paxinos, 1974). While peripherally-induced anosmia has generally failed to mimic the effects of bilateral bulbectomy on social behaviors in several rodent species (Cain \& Paxinos, 1974; Edwards, Thompson, \& Burge, 1972; Powers \& Winans, 1973; Rowe \& Smith, 1972), in male hamsters anosmia produced by destroying the olfactory bulbs might contribute heavily to deficits in aggressive behavior. This possibility is indicated by the observation that zinc-sulphate-induced anosmia reduced aggressiveness in male hamsters (Devor \& Murphy, 1973).

The second issue raised by the present data concerns the nature of the neurophysiological deficit underlying behavioral changes produced by bulbectomy. Conceivably, bulbectomy-induced changes in both social and nonsocial behaviors could be manifestations of a common neurophysiological deficit. For example, Cain (1974) has recently proposed that many of the behavioral deficits seen following bulbectomy are a consequence of bulbectomy-induced changes in the excitability of other limbic forebrain structures. On the other hand, complete bilateral destruction of the olfactory bulbs could result in the disruption of several neural mechanisms, each of which is normally involved in the mediation of only one or a few behaviors. The latter possibility gains plausibility from observations indicating that complete and subtotal olfactory bulb ablations produce different behavioral effects (Sieck \& Gordon, 1972). Whether or not social behaviors such as sex and aggression can be differentially influenced by destruction of discrete areas within the olfactory bulbs remains to be determined.

\section{REFERENCES}

Bermant, G., \& Taylor, L. Interactive effects of experience and olfactory bulb lesions in male rat copulation. Physiology and Behavior, 1969, 4, 13-17.

Borer, K. T., Powers, J. B., Winans, S. S., \& Valenstein, E. S. Infiuence of olfactory bulb removal on ingestive behaviors, activity levels, and self-stimulation in hamsters. Journal of Comparative and Physiological Psychology, 1974, 86, 396-403.

Cain, D. P. The role of the olfactory bulb in limbic mechanisms. Psychological Bulletin, 1974, 81, 654-671.

Cain, D. P., \& Paxinos, G. Olfactory bulbectomy and mucosal damage: Effects on copulation, irritability, and interspecific aggression in male rats. Journal of Comparative and Phgression in male rats. Journal of

Carter, C. S. Olfaction and sexual receptivity in the female golden hamster. Physiology and Behavior, 1973, 10, 47-51.

Denenberg, V. H. Critical periods, stimulus input, and emotional reactivity: A theory of infantile stimulation. Psychological Review, 1964, 71, 335-351.

Denenberg, V. H. Gaulin-Kremer, E., Gandelman, R., \& Zarrow, M. X. The development of standard stimulus animals for mouse (Mus musculus) aggression testing by means of olfactory bulbectomy. Animal Behavior, 1973, 21, 590-598.

Devor, M., \& Murphy, M. R. The effect of peripheral olfactory blockade on the social behavior of the male golden hamster. Behavioral Biology, 1973, 9, 31-42.

Douglas, R. J., Isaacson, R. F., \& Moss, R. F. Olfactory lesions, emotionality, and activity. Physiology and Behavior, 1969, 4, 379-381.

Edwards, D. A., Thompson, M. L., \& Burge, K. G. Olfactory bulb removal vs. peripherally induced anosmia: Differential effects on the aggressive behavior of male mice. Behavioral Biology, 1972, 7, 823-828.

Edwards, D. A., \& Warner, P. Olfactory bulb removal facilitates the hormonal induction of sexual receptivity in the female rat. Hormones and Behavior, 1972, 3, 321-332.

Goodman, E. D., \& Firestone, M. I. Olfactory bulb lesions: Nest reinforcement and handling reactivity in hamsters. Physiology and Behavior, 1973, 10, 1-8.

Heimer, L., \& Larsson, K. Mating behavior of male rats after olfactory bulb lesions. Physiology and Behavior, 1967, 2 , 207-209.

King, F. A. Effects of septal and amygdaloid lesions on emotional behavior and conditioned avoidance responses in the rat. Journal of Nervous and Mental Disease, 1958, 126, 57-63.

Leonard, C. M. Effects of neonatal (Day 10) olfactory bulb lesions on social behavior of female golden hamsters (Mesocricetus auratus). Joumal of Comparative and Physiological Psychology, 1972, 80, 208-215.

Moss, R. F. Modification of copulatory behavior in the female rat following olfactory bulb removal. Journal of Comparative and Physiological Psychology, 1971, 74, 374-382.

Murphy, M. R., \& Schneider, G. E. Oifactory bulb removal eliminates mating behavior in the male golden hamster. Science, 1970, 167, 302-304.

Powers, J. B., \& Winans, S. S. Sexual behavior in peripherally anosmic male hamsters. Physiology and Behavior, 1973, 10 , 361-368.

Richman, C. L., Gulkin, R., \& Knoblock, K. Effects of bulbectomization, strain, and gentling on emotionality and 
exploratory behavior in rats. Physiology and Behavior, 1972, 8, 447-452.

Ropartz, $P$. The relation between olfactory stimulation and aggressive behavior in mice. Animal Behavior, 1968, 16, 97-100.

Rowe, F. A., \& Edwards, D. A. Olfactory bulb removal: Influences on the aggressive behaviors of male mice. Physiology and Behavior, 1971, 7, 889-892.

Rowe, F. A., \& Edwards, D. A. Olfactory bulb removal: Influences on the mating behavior of male mice. Physiology and Behavior, 1972, 8, 37-41.

Rowe, F. A., \& Smith, W. E. Effects of peripherally induced anosmia on mating behavior of mice. Psychonomic Science, $1972,27,33-34$.

Sieck, $M$. $H$. The role of the olfactory system in avoidance learning and activity changes. Physiology and Behavior, 1972, 8, 705-710.
Sieck, M. H., \& Gordon, B. L. Selective olfactory bulb lesions: Reactivity changes and avoidance learning in rats. Physiology and Behavior, 1972, 9, 545-552.

Sieck, M. H., \& Gordon, B. L. Anterior olfactory nucleus or lateral olfactory tract destruction in rats and changes in appetitive and aversive behavior. Physiology and Behavior, $1973,10,1051-1059$.

Thompson, M. L., \& Edwards, D. A. Olfactory bulb removal impairs the induction of sexual receptivity in spayed female mice. Physiology and Behavior, 1972, 8, 1141-1146.

Whimbey, A. E., \& Denenberg, V. H. Two independent behavioral dimensions in open-field performance. Journal of Comparative and Physiological Psychology, 1967, 63, 500-504.

(Received for publication August 20, 1974; revision received November 22,1974 .) 